\title{
Maternal Euthyroid Hyperthyroxinemia May Reduce Preterm Birth Rate in Multiparous Women
}

\author{
Pompilio Torremante ${ }^{1}$, Wolf Kirschner ${ }^{2}$, Rainer Muche ${ }^{3}$, Felix Flock ${ }^{4}$ \\ ${ }^{1}$ Practice for Gynecology and Obstetrics, Ochsenhausen, Germany \\ ${ }^{2}$ Institute for Research, Consultation and Evaluation, Berlin, Germany \\ ${ }^{3}$ Institute for Biometry and Epidemiology, University of Ulm, Ulm, Germany \\ ${ }^{4}$ Department of Obstetrics and Gynecology at the Medical Centre of Memmingen, Memmingen, Germany \\ Email: dr.torremante@onlinemed.de
}

How to cite this paper: Torremante, P., Kirschner, W., Muche, R. and Flock, F. (2017) Maternal Euthyroid Hyperthyroxinemia May Reduce Preterm Birth Rate in Multiparous Women. Open Journal of Obstetrics and Gynecology, 7, 623-638. https://doi.org/10.4236/ojog.2017.76065

Received: March 20, 2017

Accepted: June 13, 2017

Published: June 16, 2017

Copyright (c) 2017 by authors and Scientific Research Publishing Inc. This work is licensed under the Creative Commons Attribution International License (CC BY 4.0).

http://creativecommons.org/licenses/by/4.0/

\begin{abstract}
Hypothyroidism, defined as thyrotropin (TSH) above and free thyroxine (fT4) serum level below the reference rage, as well as hyperthyroidism, defined as suppressed TSH and elevated thyroid hormones exceeding the upper limit of the reference range, may have major impacts on fertility and pregnancy outcome. Ideally, euthyroidism, defined as TSH and fT4 in the reference range, should be established and preserved during pregnancy prior to gestation. High estrogen levels during pregnancy stimulate the synthesis of maternal thyroxine-binding-globulin (TBG) in the liver, increasing TBG serum concentration by 2 - 3 fold compared to the initial value and affecting thus maternal fT4 serum level. As a consequence, maternal thyroid function adapts by increasing synthesis and secretion of thyroxine. TBG-induced elevation of serum thyroxine either total or free in the absence of hyperthyroidism is defined as euthyroid hyperthyroxinemia. Since TBG concentration declines first after delivery, pregnancy-induced euthyroid hyperthyroxinemia constitutes a physiological metabolic state. Depending on functional capacity, maternal thyroid may exhaust, resulting in hypothyroxinemia, which increases the risk of fetal neurodevelopmental impairment and preterm birth. The study aims to determine whether L-Thyroxine (L-T4) replacement, sustaining pregnancy-induced maternal euthyroid hyperthyroxinemia during the whole pregnancy by keeping fT4 level in the high normal reference range might reduce preterm birth rate. Preterm birth rate of women with singleton gestation and L-T4induced high normal fT4 level constituting the study group $(n=918)$ was compared with the preterm birth rate of women with singleton gestation ( $\mathrm{n}=$ 6414) who completed a questionnaire concerning L-T4 administration during pregnancy. Two groups were formed. In group A we compared the preterm
\end{abstract}


birth rate between women with L-T4-induced high normal fT4 level and a control group without L-T4 administration during pregnancy. In group B we compared the preterm birth rate of women already receiving L-T4 prior to conception, maintaining dosage to keep fT4 level in the high normal reference range during gestation to a control group with L-T4 intake during pregnancy. The preterm birth rates in group A declined by $51 \%(\mathrm{p}=0.01)$ and in group $\mathrm{B}$ by $87 \%(\mathrm{p}=0.001)$ in multiparous women, while in primiparous the preterm birth rate was similar between study and the control group. Sustaining a high normal fT4 level during pregnancy with L-T4 may significantly reduce preterm birth rate in multiparous women.

\section{Keywords}

Preterm Birth, Euthyroid Hyperthyroxinemia, Thyroid, Pregnancy

\section{Introduction}

Despite remarkable progress in perinatal medicine, preterm birth remains an unresolved obstetrical challenge with an estimated worldwide prevalence of $11 \%$ of all live-births, accounting for nearly 15 million babies born before 37 weeks of gestation. Over $50 \%$ of all neonatal deaths are due to prematurity and many survivors may have long-term adverse health deficits [1].

Preterm birth has multifactorial causes. These encompass advanced age or teenage pregnancy, parity, ethnicity, history of cervical cone biopsy, low as well as high body mass index, tobacco use, assisted conception with in vitro fertilization, and gamete intrafallopian transfer, especially for singleton gestations, systemic and genital-tract infection, and low parental socioeconomic status, being the most important factors [2] [3] [4] [5].

In the last decades numerous epidemiological studies suggest that maternal hypothyroxinemia during pregnancy increases the risk for delayed neurobehavioral development and cognitive function in childhood [6]. Pregnancy outcome, especially the risk of preterm birth, might also be jeopardized by maternal hypothyroxinemia, although most results from epidemiological studies are not unique and a clear interrelationship between maternal hypothyroxinemia and preterm birth is not well established [7]. Rather, no effect of maternal hypothyroxinemia in pregnancy outcome could be found in two recently published studies [8] [9].

The official recommendations concerning diagnosis and treatment of thyroid disease in USA and Europe vary. The American College of Obstetricians and Gynecologists does not recommend routine screening for thyroid disease in pregnancy. Even treatment of subclinical hypothyroidism is questioned because convincing data for adverse pregnancy outcome are lacking. The American Thyroid Association agrees with the exception that women with subclinical hypothyroidism associated with thyroid peroxidase antibody (TPO) positivity should be treated with L-T4. Finally, Endocrine Society Guidelines of 2011 al- 
ready left the choice of treatment to the discretion of the caregiver [10] [11] [12].

The European Thyroid Association acknowledges that maternal hypothyroxinemia may impair neuropsychological development in the offspring. Therefore, universal thyroid screening is considered to be justified by the majority of authors, although it is stated that well controlled studies are lacking. They acknowledge that subclinical hypothyroidism and isolated hypothyroxinemia detected in the first trimester should be treated with L-T4 to avoid neuropsychological impairment in children and adverse pregnancy outcome [13].

In 2011, we demonstrated a lower preterm birth rate in multiparous women by keeping maternal fT4 serum level with L-T4 in the high normal reference range [14]. The aim of this study is to confirm our previously published results by expanding the former study population and comparing the preterm birth rate with a control group with known administration of L-T4 during pregnancy. Considering emerging concerns, we additionally analyzed the potential relationship between high-normal maternal fT4 levels in early pregnancy and increased risk for small gestational age (SGA) newborns [15] [16].

\section{Subjects and Methods}

This clinical trial is a retrospective nonrandomized observational study with prospectively designed data. All pregnant women below 12 weeks of gestation presenting for their first medical consultation for prenatal care in a medical office in Southern Germany were offered a serological thyroid scan. An early ultrasound of the crown-rump length was used to correct gestational age when the difference using the last menstrual period was equal to or greater than 7 days. The serological thyroid scan included basal TSH, free triiodothyronine (fT3), free thyroxine (fT4) and thyroid antibodies. Thyroid antibodies were not further considered for this study evaluation. To all pregnant women with fT4 values below the upper third of the reference range (high normal values), L-T4 was prescribed with the intention to keep fT4 levels in the upper third of the reference range (high normal values) until delivery. If fT4 values were found to be in the upper third of the reference range L-T4 was not administered until the values began to decline. Maternal fT4 serum levels were regularly assessed after an interval of 24 hours from the last L-T4 intake every 4 weeks during routinely performed serological scans for pregnancy care and if necessary, the L-T4 dose was adjusted. Additionally, each woman ingested supplements containing 150 or 200 $\mu \mathrm{g}$ iodide and $400 \mu \mathrm{g}$ folic acid. Preterm birth was defined as delivery before completed 37 weeks of gestation. Overall, 918 pregnant women with singleton gestation, 383 primiparous and 535 multiparous were included in the study group covering a time span from august 2001 until December 2015. The control group encompassed 6414 pregnant women with singleton gestation, 4338 primiparous and 2076 multiparous from the "Baby Care" surveillance program who had completed a questionnaire about preterm birth risks, daily nutrition, and medication intake during pregnancy with particular consideration of L-T4 administration. 
"Baby Care" is a written advisory program for early detection of pregnancy risks with special emphasis on preterm birth. Based on a questionnaire, all relevant risk factors for preterm birth are inquired. It includes further individual counseling with respect to medication in pregnancy, specific personal recommendations to reduce preterm birth risks and a 7-day food record of the German Society for Nutrition to determine the individual intake of micronutrients. Since 2000 , this voluntary program is available by gynecological offices and health insurance companies throughout Germany with a database of more than 60.000 participants.

In our previously published study [14], the preterm birth lowering effect of induced high normal fT4 serum levels with L-T4 was only prevalent in multiparous women. To rule out heterogeneity of the risk factors and to avoid possible selection, we first compared the odds ratios of preterm birth risks in a sample of multiparous of the study and control groups. From the $\mathrm{n}=535$ multiparous women in the study group, $\mathrm{n}=60(11 \%)$ had also completed the "Baby Care" questionnaire. This sample was compared with a sample $n=243$ of participants of the "Baby Care" program who completed the questionnaire from the same regional origin in South Germany (Table 1).

Table 1. Comparison of the prevalence of risk factors for preterm birth between study group and control group from the same regional origin in South Germany.

\begin{tabular}{|c|c|c|c|c|}
\hline & $\begin{array}{l}\text { Study } \\
\text { group }\end{array}$ & $\begin{array}{c}\text { Control } \\
\text { group }\end{array}$ & & \\
\hline Risk factors of preterm birth & $\mathrm{n}=60$ & $\mathrm{n}=243$ & Odds ratio & CI $(95 \%)$ \\
\hline Low and middle school education status & $88.3 \%$ & $60.2 \%$ & 5.01 & $2.19-11.49$ \\
\hline Thyroid disease in last 12 months & $23.3 \%$ & $9.1 \%$ & 3.06 & $1.46-6.42$ \\
\hline Smoking at diagnosis of pregnancy & $27.6 \%$ & $13.5 \%$ & 2.45 & $1.23-4.87$ \\
\hline Diabetes in last 12 months & $1.7 \%$ & $0.4 \%$ & 4.10 & $0.25-66.55$ \\
\hline Hypertension in last 12 months & $5.0 \%$ & $3.3 \%$ & 1.55 & $0.40-6.01$ \\
\hline Hospital admission(s) in last 12 months & $21.7 \%$ & $17.7 \%$ & 1.29 & $0.64-2.58$ \\
\hline Body mass index $(\geq 25,<25)$ & $28.3 \%$ & $25.5 \%$ & 1.15 & $0.61-2.17$ \\
\hline Gynecological surgery ever & $44.0 \%$ & $41.2 \%$ & 1.12 & $0.60-2.09$ \\
\hline Former preterm birth & $13.3 \%$ & $12.4 \%$ & 1.08 & $0.47-2.50$ \\
\hline Self-assessed health status & $25.0 \%$ & $24.5 \%$ & 1.03 & $0.53-1.98$ \\
\hline Psychological Stress & $32.1 \%$ & $33.6 \%$ & 0.94 & $0.50-1.75$ \\
\hline Vaginal infection(s) in last 12 months & $11.1 \%$ & $12.5 \%$ & 0.88 & $0.09-8.56$ \\
\hline Former miscarriage(s) & $25.0 \%$ & $32.1 \%$ & 0.71 & $0.37-1.34$ \\
\hline Further complications in former pregnancies & $40.0 \%$ & $50.4 \%$ & 0.66 & $0.37-1.16$ \\
\hline Age $\geq 30$ years $/<30$ years & $71.7 \%$ & $81.5 \%$ & 0.57 & $0.30-1.10$ \\
\hline Former induced abortion & $6.7 \%$ & $11.1 \%$ & 0.57 & $0.19-1.70$ \\
\hline Fertility treatment & $8.3 \%$ & $27.7 \%$ & 0.24 & $0.09-0.62$ \\
\hline
\end{tabular}

$\mathrm{CI}=$ Confidence interval . 
With regard to lower school qualification, smoking habits and thyroid disease, Table 1 indicates a significantly higher prevalence in the study group compared to the control group, while the prevalence of the other risk factors did not differ. According to a meta-analysis, smoking is a relevant risk factor for preterm birth with a calculated odds-ratio of $1.27(1.21-1.33)$, as well as low education level with an odds-ratio up to 1.4 [17] [18]. Thus, the study group had higher prevalence of risk factors for preterm birth in multiparous women.

To compare the preterm birth rates in the study and control group, two collectives were formed. In group A we compared the preterm birth rate between women with L-T4-induced high normal fT4 level and a control group without L-T4 administration during pregnancy. In group B we compared the preterm birth rate of women already receiving L-T4 prior to conception, maintaining dosage to keep fT4 level in the high normal reference range during gestation to a control group with L-T4 intake during pregnancy.

Group A encompassed in the study group 615 pregnant women, 240 primiparous and 375 multiparous. Those women who did not ingest L-T4 prior to gestation were prescribed L-T4 to keep the fT4 level in the high normal reference range (upper third). If these women had preexisting high normal fT4 levels, L-T4 was first started when levels began to decline. The control group consisted of 5579 pregnant women, 3781 primiparous and 1798 multiparous without L-T4 administration during pregnancy.

Group B consisted in the study group of 303 pregnant women, 143 primiparous and 160 multiparous. These women were already taking L-T4 prior to conception. The administration of L-T4 was continued but if fT4 was not in the high normal reference range (upper third) the dose was increased in order to elevate maternal fT4 serum levels in the high normal reference range. The control group encompassed 835 pregnant women, 557 primiparous and 278 multiparous who according to the questionnaire had administered L-T4 during gestation. Table 2 indicates the study group A and B by mean age, parity status and induced high normal fT4 levels.

We further examined whether induced maternal high normal fT4 levels with L-T4 might increase the prevalence of SGA newborns. SGA was defined as a birth weight below the $5^{\text {th }}$ percentile for gestational age.

The study was approved by the Ethics Commission of the National Medical Association of Baden-Wuerttemberg, Germany.

Table 2. Overview of the study group A and control group B.

\begin{tabular}{cccccccc}
\hline \multicolumn{4}{c}{ Group A } & \multicolumn{4}{c}{ Group B } \\
\hline \multicolumn{2}{c}{ Primiparous } & \multicolumn{2}{c}{ Multiparous } & \multicolumn{2}{c}{ Primiparous } & \multicolumn{2}{c}{ Multiparous } \\
\hline Study* & Control & Study & Control & Study* & Control & Study* & Control \\
\hline $\mathrm{n}=240$ & $\mathrm{n}=3781$ & $\mathrm{n}=375$ & $\mathrm{n}=1798$ & $\mathrm{n}=143$ & $\mathrm{n}=557$ & $\mathrm{n}=160$ & $\mathrm{n}=278$ \\
$\mathrm{Ma} \pm \mathrm{SD}$ & $\mathrm{Ma} \pm \mathrm{SD}$ & $\mathrm{Ma} \pm \mathrm{SD}$ & $\mathrm{Ma} \pm \mathrm{SD}$ & $\mathrm{Ma} \pm \mathrm{SD}$ & $\mathrm{Ma} \pm \mathrm{SD}$ & $\mathrm{Ma} \pm \mathrm{SD}$ & $\mathrm{Ma} \pm \mathrm{SD}$ \\
$28.3 \pm 5.1$ & $30.6 \pm 4.1$ & $30.6 \pm 4.1$ & $32.4 \pm 4.3$ & $30.3 \pm 4.6$ & $31.7 \pm 3.9$ & $32.8 \pm 5.0$ & $33.4 \pm 4.3$ \\
\hline
\end{tabular}

* $=\mathrm{fT} 4$ in the high normal reference range (upper third), $\mathrm{Ma} \pm \mathrm{SD}=$ Mean age \pm Standard deviation. 


\section{Laboratory Analysis}

Serum basal TSH and fT4 were measured using a third-generation electrochemiluminescence immunoassay (Elecsys 1010/2010-MODULAR ANALYTICS E170 from Roche Diagnostics GmbH-Mannheim, Germany). Between 2001 and 2010, trimester specific reference values for TSH and fT4 were not available, so the reference range for non-pregnant women was used as recommended [11]. Reference values for TSH were $0.27-4.2 \mu \mathrm{IU} / \mathrm{ml}$ and for fT4 $12.14-19.62$ $\mathrm{pmol} / \mathrm{l}$. Intra- and inter-assay coefficients of variation were $3.0 \%$ and $7.2 \%$ for TSH, and 1.4\% and 3.5\% for fT4. From 2011 to 2015 trimester specific reference ranges for TSH and fT4 were used. The TSH reference range for the first trimester was $0.1-2.5 \mu \mathrm{U} / \mathrm{ml}$, for the second trimester it was $0.2-3.0 \mu \mathrm{U} / \mathrm{ml}$ and for the third trimester it was $0.3-3.0-3.5 \mu \mathrm{U} / \mathrm{ml}$. The reference range for fT4 in the first trimester was $11.6-19.3 \mathrm{pmol} / \mathrm{l}$, in the second trimester $9.0-16.7 \mathrm{pmol} / \mathrm{l}$ and in the third trimester $9.0-15.4 \mathrm{pmol} / \mathrm{l}$.

\section{Statistical analysis}

We compared treated women and controls in group A as well as group B separately for primiparous and multiparous. Since number and distribution regarding age were different between cases and controls in these groups, a weighting adjustment was performed and preterm birth rates were evaluated by means of the Chi-Square test with a p-value $<0.05$ considered as statistical significant.

\section{Results}

In group $A$ the preterm birth rate for primiparous in the study group was 9.3\% versus $7.3 \%$ in the control group indicating no statistical difference $(\mathrm{p}=0.16)$. For multiparous, the preterm birth rate in the study group was $3.4 \%$ versus $7.0 \%$ in control group, resulting in a reduction of $51 \%$, which is highly significant (Table 3).

In group B the preterm birth rate for primiparous in the study group was 5.6\% versus $10.2 \%$ in the control group. This is a reduction by $45 \%$, however not yet significant $(\mathrm{p}=0.08)$. For multiparous, the preterm birth rate in the study group was $1.2 \%$ versus $9.4 \%$ in the control group, resulting in a highly significant reduction by $87 \%$ (Table 4 ).

To keep maternal fT4 serum levels in the high normal reference range in group A, the following L-T4 doses indicated by mean \pm SD and [median] were administered. During first, second and third trimester the L-T4 dose was $39 \mu \mathrm{g} \pm$ $48.6 \mu \mathrm{g}$ [0], $107.8 \mu \mathrm{g} \pm 51.7 \mu \mathrm{g}[100 \mu \mathrm{g}]$ and $152.4 \mu \mathrm{g} \pm 54.18 \mu \mathrm{g}[150 \mu \mathrm{g}]$, respectively. The corresponding TSH readings indicated by mean \pm SD and [median]

Table 3. Comparison of preterm birth rates in group A.

\begin{tabular}{lll}
\hline & Primiparous & Multiparous \\
\hline Study group $(\mathrm{n}=\mathbf{6 1 5})$ & $9.3 \%$ & $3.4 \%$ \\
Control group $(\mathrm{n}=\mathbf{5 5 7 9})$ & $7.3 \%$ & $7.0 \%$ \\
Significance $\mathrm{p}<\mathbf{0 . 0 5}$ & $\mathrm{p}=0.16$ & $\mathrm{p}=0.01$ \\
\hline
\end{tabular}

* = fT4 in the high normal reference range (upper third). 
Table 4. Comparison of preterm birth rates in group B.

\begin{tabular}{ccc}
\hline & Primiparous & Multiparous \\
\hline Study group* $(\mathrm{n}=\mathbf{3 0 3})$ & $5.6 \%$ & $1.2 \%$ \\
Control group $(\mathrm{n}=\mathbf{8 3 5})$ & $10.2 \%$ & $9.4 \%$ \\
Significance $\mathrm{p}<\mathbf{0 . 0 5}$ & $\mathrm{p}=0.08$ & $\mathrm{p}=0.001$ \\
\hline
\end{tabular}

* = fT4 in the high normal reference range (upper third).

were $1.43 \mu \mathrm{U} / \mathrm{ml} \pm 1.5 \mu \mathrm{U} / \mathrm{ml}[1.25 \mu \mathrm{U} / \mathrm{ml}], 0.48 \mu \mathrm{U} / \mathrm{ml} \pm 0.64 \mu \mathrm{U} / \mathrm{ml}[0.12$ $\mu \mathrm{U} / \mathrm{ml}]$ and $0.32 \mu \mathrm{U} / \mathrm{ml} \pm 0.63 \mu \mathrm{U} / \mathrm{ml}[0.05 \mu \mathrm{U} / \mathrm{ml}]$, respectively. The corresponding fT4 readings indicated by mean \pm SD and [median] were $16.1 \mathrm{pmol} / \mathrm{l} \pm$ $2.7 \mathrm{pmol} / \mathrm{l}$ [15.7 pmol/l], $16.0 \mathrm{pmol} / \mathrm{l} \pm 3.5 \mathrm{pmol} / \mathrm{l}[15.7 \mathrm{pmol} / \mathrm{l}]$ and $16.7 \mathrm{pmol} / \mathrm{l}$ $\pm 3.1 \mathrm{pmol} / \mathrm{l}$ [16.7 pmol/l], respectively (Table 5).

As indicated in Table 5, only during the third trimester median fT4 readings exceeded the upper limit of the reference range, but TSH was in most cases lower than the lower limit of the reference range, suggesting biochemical subclinical hyperthyroidism.

For group B, the following L-T4 doses indicated by mean \pm SD and [median] were administered. During first, second and third trimester the L-T4 dose was $89.6 \mu \mathrm{g} \pm 47.1 \mu \mathrm{g}[100 \mu \mathrm{g}], 130.9 \mu \mathrm{g} \pm 52.3 \mu \mathrm{g}[150 \mu \mathrm{g}]$ and $167.5 \mu \mathrm{g} \pm 54.4 \mu \mathrm{g}$ $[150 \mu \mathrm{g}]$, respectively. The corresponding TSH readings indicated by mean \pm SD and [median] were $0.82 \mu \mathrm{U} / \mathrm{ml} \pm 1.29 \mu \mathrm{U} / \mathrm{ml}[0.36 \mu \mathrm{U} / \mathrm{ml}], 0.42 \mu \mathrm{U} / \mathrm{ml} \pm 1.87$ $\mu \mathrm{U} / \mathrm{ml}[0.05 \mu \mathrm{U} / \mathrm{ml}]$ and $0.21 \mu \mathrm{U} / \mathrm{ml} \pm 0.43 \mu \mathrm{U} / \mathrm{ml}[0.05 \mu \mathrm{U} / \mathrm{ml}]$, respectively. The corresponding $\mathrm{fT} 4$ readings indicated by mean $\pm \mathrm{SD}$ and [median] were $18.3 \mathrm{pmol} / \mathrm{l} \pm 4.0 \mathrm{pmol} / \mathrm{l}$ [17.6 pmol/l], $16.6 \mathrm{pmol} / \mathrm{l} \pm 2.7 \mathrm{pmol} / 1$ [16.5 pmol/l] and $17.2 \mathrm{pmol} / \mathrm{l} \pm 2.8 \mathrm{pmol} / 1$ [17.0 pmol/l] , respectively (Table 6).

Median fT4 reading during the third trimester only slightly exceeded the upper limit of the reference range but again in group B TSH was mostly lower than the lower end of reference range, suggesting biochemical subclinical hyperthyroidism as well.

Due to the impaired thyroid function of the women in study group B a higher

Table 5. Thyroid parameters TSH and fT4 related to L-T4 doses in the study group A $(n=615)$.

\begin{tabular}{ccc}
\hline & TSH & fT4 \\
\hline 1. Trimester & RR: $0.1-2.5 \mu \mathrm{U} / \mathrm{ml}$ & RR: $11.6-19.3 \mathrm{pmol} / 1$ \\
Until 12. weeks & $(\mathrm{n}=488)$ & $(\mathrm{n}=959)$ \\
Mean + SD [Median] & $1.43 \pm 1.5[1.25]$ & $16.1 \pm 2.7[15.7]$ \\
2. Trimester & RR: $0.2-3.0 \mu \mathrm{U} / \mathrm{ml}$ & RR: $\mathbf{9 . 0}-\mathbf{1 6 . 7} \mathrm{pmol} / 1$ \\
Between 13.-28. weeks & $(\mathrm{n}=513)$ & $(\mathrm{n}=2076)$ \\
Mean + SD [Median] & $0.48 \pm 0.64[0.12]$ & $16.0 \pm 3.5[15.7]$ \\
3. Trimester & RR: $0.3-3.0-3.5 \mu \mathrm{U} / \mathrm{ml}$ & RR: $9.0-15.4 \mathrm{pmol} / 1$ \\
Over $>$ 29. weeks & $(\mathrm{n}=310)$ & $(\mathrm{n}=1134)$ \\
Mean + SD [Median] & $0.32 \pm 0.63[0.05]$ & $16.7 \pm 3.1[16.7]$
\end{tabular}

$\mathrm{n}=$ number of readings, $\mathrm{RR}=$ pregnancy specific reference range, $\mathrm{SD}=$ standard deviation. 
Table 6. Thyroid parameters TSH and fT4 related to L-T4 doses in the study group B ( $\mathrm{n}=303)$.

\begin{tabular}{|c|c|c|c|}
\hline & TSH & fT4 & L-T4 -dose \\
\hline 1. Trimester & RR: $0.1-2.5 \mu \mathrm{U} / \mathrm{ml}$ & RR: 11.6 - $19.3 \mathrm{pmol} / 1$ & \\
\hline Until 12. weeks & $(n=216)$ & $(\mathrm{n}=534)$ & $(\mathrm{n}=533)$ \\
\hline Mean + SD [Median] & $0.82 \pm 1.29[0.36]$ & $18.3 \pm 4.0[17.6]$ & $89.6 \pm 47.1 \mu \mathrm{g}[100 \mu \mathrm{g}]$ \\
\hline 2. Trimester & $\mathrm{RR}: 0.2-3.0 \mu \mathrm{U} / \mathrm{ml}$ & RR: 9.0 - $16.7 \mathrm{pmol} / 1$ & \\
\hline Between 13.-28. weeks & $(\mathrm{n}=351)$ & $(\mathrm{n}=1083)$ & $(\mathrm{n}=1084)$ \\
\hline Mean + SD [Median] & $0.42 \pm 1.87[0.05]$ & $16.6 \pm 2.7[16.5]$ & $130.9 \pm 52.3 \mu \mathrm{g}[150 \mu \mathrm{g}]$ \\
\hline 3. Trimester & RR: $0.3-3.0-3.5 \mu \mathrm{U} / \mathrm{ml}$ & RR: 9.0 - $15.4 \mathrm{pmol} / 1$ & \\
\hline Over $>29$. weeks & $(\mathrm{n}=198)$ & $(\mathrm{n}=577)$ & $(\mathrm{n}=577)$ \\
\hline Mean + SD [Median] & $0.21 \pm 0.43[0.05]$ & $17.2 \pm 2.8[17.0]$ & $167.5 \pm 54.4 \mu \mathrm{g}[150 \mu \mathrm{g}]$ \\
\hline
\end{tabular}

$\mathrm{n}=$ number of readings, $\mathrm{RR}=$ pregnancy specific reference range, $\mathrm{SD}=$ standard deviation.

L-T4 dose was needed to increase fT4 serum level towards the high normal reference range during the first trimester, $89.6 \pm 47.1 \mu \mathrm{g}$ versus $39.0 \pm 48.6 \mu \mathrm{g}$ and became similar to group A during the second and third trimester (Table 5, Table 6). In both groups, TSH readings were very low and fT4, as intended, high, indicating in both groups biochemical subclinical hyperthyroidism. Major influence factors for biochemical hyperthyroidism were frequently disregarded interval between the last L-T4 ingestion and TSH reading, which should be ideally 24 hours before blood drawing and an insufficiently short period of 4 weeks for establishing a new steady-state between peripheral fT4 serum level and the hypothalamus-pituitary axis which affects TSH levels. Nevertheless, L-T4 was generally tolerated very well, without any signs of maternal or fetal hyperthyroidism. Maternal side effects such as palpitations occurred sporadically and resolved by reducing the L-T4 dose. Fetal signs of induced hyperthyroidism controlled by ultrasound check and cardiotocography never occurred.

Concerning the rate of newborns with SGA in the study groups it was 5.5\% versus $5.0 \%(p=0.4)$ in control groups, and thus not significantly different.

\section{Discussion}

The present observational investigation confirms our previous data that L-T4, administered to keep maternal fT4 serum levels in the upper third of the reference ranges, which is high normal during pregnancy, may effectively and safely reduce preterm birth rate in multiparous women, and this applies in particular to women who were already taking L-T4 prior to conception. Regarding our published data in 2011, the presented results suggest that the preterm birth lowering effects of high normal fT4 seem to be independent of the use of trimester specific reference ranges [14]. Our data did not confirm an association between high normal maternal fT4 serum levels and an increased risk for SGA newborns. This is in accordance with a newly published meta-analysis [16].

In two recently performed randomized trials, which aimed to treat pregnant women with L-T4 suffering from subclinical hypothyroidism or hypothyrox- 
inemia to improve cognitive function of the offspring, no effect on preterm birth rate was observed. As mentioned by the authors, both studies have the limitation that they started too late in gestation with L-T4 treatment. L-T4 was administered after the first trimester at a median gestational age of 13 weeks 3 days in one and at 16 weeks 4 days and 18 weeks in the other study. Furthermore, both studies had only the intention to establish euthyroidism by keeping TSH in the low normal or normal and fT4 in the reference range. It was not considered that pregnancy induces physiological euthyroid hyperthyroxinemia and that fT4 can be safely held in the high normal reference range without impairing maternal or fetal health [8] [9].

High pregnancy estrogen levels selectively induce maternal and fetal serum TBG synthesis in the liver while the other two thyroxine binding proteins, transthyretin (TTR) and albumin, remain unchanged or decline with only minimal effects on fT4 concentration. Maternal TBG concentration increases by 2 3 fold compared to the initial value and by increased sialic acid content, TBG serum half-life is prolonged, resulting in TBG excess. At mid-gestation, maternal TBG concentration reaches a plateau, remaining nearly unchanged until term and declining only after parturition. This physiological changeover in maternal serum might presumably be the most important impact for thyroid function during gestation [19] [20].

As a consequence, maternal thyroid function has to adapt, since any change in the affinity or capacity of plasma binding proteins will alter the relationship between circulating total and free hormones. A decreased fT4 level by increased TBG binding triggers normal pituitary-thyroid axis to maintain the appropriate free hormone concentration and stimulates thyroid hormone synthesis and secretion. Since TBG has a 20 fold greater affinity to T4 than to T3, high TBG levels affect serum fT4 more than serum fT3. The T3 and fT3 serum levels remain stable or decline during pregnancy [21]. Of the three binding proteins, TBG has the highest affinity to T4 which is not modified by pregnancy, and it carries the highest proportion of T4 [19] [20].

In the fetus, TBG is the main T4 binding protein, since concentration of TTR and albumin is low. TBG synthesis increases rapidly up to 24 weeks of gestation, and correlates with the crown-rump length. By 24 weeks of gestation more than $83 \%$ of T4 is bound to TBG, which is much higher than in non-pregnant women [22] [23]. Between 24 weeks and term, TBG concentration reaches adult levels, tripling the TBG capacity during this period [24] [25].

TBG-induced elevation of serum T4, either total or free, in the absence of hyperthyroidism, concomitant with low, normal or high levels of T3 is defined as euthyroid hyperthyroxinemia and TBG excess is the most common cause of hyperthyroxinemia, naturally occurring during pregnancy [26] [27]. Because TBG concentration declines only after delivery, pregnancy-induced maternal euthyroid hyperthyroxinemia seems to be a physiological metabolic state. Consequently, a decline in maternal fT4 serum level with advancing pregnancy might be a sign of thyroid function exhaustion which leads to progressive TBG 
desaturation with persistent high TBG concentration [19].

To achieve the higher T4 demand, maternal thyroid is stimulated by human chorionic gonadotropin (hCG) which has thyrotropic activity during the first trimester. The stimulatory effect of TSH and hCG on maternal thyroid differ significantly from each other. While TSH promotes preferentially T3 synthesis and secretion, hCG preferentially induces the release of T4 in high quantities leading in general to TSH suppression and therefore inhibiting further thyroidal T3 secretion [20] [28] [29] [30]. HCG can override the hypothalamic-pituitarythyroid feedback system, forcing maternal thyroid to synthesize and secrete high quantities of T4, accompanied by low or suppressed TSH and normal fT3 [25] [26] [27] [31] [32] [33].

Maternal thyroid adaptation is often associated with transitory subclinical hyperthyroidism, which is exclusively defined on laboratory findings, not on clinical complaints. Typical readings are subnormal TSH levels and free thyroid hormones fT3 and fT4 in the mid-to-high reference range [34]. During the first trimester the lower end of the reference range for TSH is poorly defined. TSH values below the classical lower limit of $0.4 \mu \mathrm{IU} / \mathrm{ml}$ and in a small percentage even suppressed below $<0.01 \mu \mathrm{IU} / \mathrm{ml}$ still represent a normal pregnancy, not indicating subclinical hyperthyroidism. Therefore, and based on studies that did not demonstrate maternal or neonatal complications with subclinical hyperthyroidism [35], some authors advocate that it might be reasonable to assume that TSH suppression can be safely maintained throughout pregnancy [11] [20] [36]. Even hCG-induced gestational transient thyrotoxicosis (GTT) is without unfavorable effects on pregnancy outcome [20] [36] [37] [38].

L-T4 substitution causes hyperthyroxinemia as well without simultaneously increasing fT3 levels, which usually remain in lower end of the reference range because thyroidal T3 secretion is inhibited by decreased or suppressed TSH [39] [40]. When L-T4 is ingested, the peripheral conversion to T3 is accomplished by autoregulation of 5'-deiodination (D1). Depending on the L-T4 dose D1 may produce $\mathrm{T} 3$ or more metabolic inactive reverse- $\mathrm{T} 3$ (rT3), when serum $\mathrm{T} 4$ concentration is elevated. Additionally, by renal and hepatic sulfation, higher L-T4 doses can be rapidly inactivated. Therefore, L-T4-induced hyperthyroxinemia concomitant with suppressed TSH does not necessarily indicate excessive dose ingestion, although biochemical signs for subclinical hyperthyroidism may be apparent [26] [41] [42].

Transplacental passage of maternal thyroid hormones is controlled by placental type 3 deiodinase (D3) which inactivates T3 over T4 with preference for T3 [43] [44]. Human tracer kinetic studies indicate that during pregnancy D3 inactivates $80 \%$ of daily thyroid hormone production, either as T4 or T3. However, it seems evident that transplacental passage of $\mathrm{T} 4$ can only be assured by binding to placental TTR, which reduces exposure to D3 to be inactivated [21]. Since the affinity of TTR for T4 is 4 fold higher than for T3 in humans, maternal T3 may be fully subject to the deactivating activity of D3 and even in high concentration cannot cross the placental barrier. Placental TTR binding of T4 contributes es- 
sentially to the preferential transmission of maternal T4 over T3 to the fetus [45] [46] [47].

Beside the placenta, fetal tissues, as well as liver, cerebral cortex and the epithelial structures of the embryonic lung, intestine, skin, and urinary tract also express D3. Similar to the uteroplacental unit, fetal D3 activity regulates the transfer of maternal thyroid hormones. The deactivating efficiency prevents fetal hyperthyroidism even when high doses of L-T4 are introduced into amniotic fluid [48] [49] [50].

Our study shows a considerable and significant reduction of the preterm birth rate for multiparous women by induced high normal fT4 level with L-T4. Nevertheless, there might be some assumption that the study group may be selected towards reduced risks of preterm birth. To avoid this assumption, a comparison of preterm birth risks between the study and control groups was performed. With regard to the established risk factors for preterm birth, namely lower school qualification, smoking habits and thyroid disease, the prevalence in the study group was significantly higher than in the control group while all other important risk factors do not significantly differ. Therefore, the preterm birth rate should be even higher in the study group compared to the control group underscoring the preterm birth lowering effect of induced high normal fT4 serum level with L-T4. However, a limitation is the retrospective approach and the restriction of analyses on a few causes for preterm birth, knowing the multifactorial background of this pregnancy complication. Therefore, we cannot exclude the possibility that our results may be subject to other aspects not considered that could also reduce preterm birth rate in multiparous women. The relationship between maternal high normal fT4 level and a possible reduction of preterm birth rate in multiparous women has never been reported before.

\section{Summary}

Based on estrogen-induced TBG excess, maternal euthyroid hyperthyroxinemia is the physiological adaptation to higher metabolic demand during pregnancy. Declining maternal fT4 serum levels are a sign of thyroid exhaustion and may be associated with adverse pregnancy outcome, especially preterm birth in multiparous women. High maternal fT4 serum levels, either endogenously synthesized or exogenously caused by administration of L-T4 are harmless for both mother and fetus and may be associated with a considerably reduced preterm birth rate in multiparous women. This applies in particular to women who are already taking L-T4 prior to conception. L-T4, one of the most widely prescribed drugs, has a safe latitude and is well tolerated during gestation. Keeping maternal fT4 in the upper third of reference range or high normal is easy to manage, harmless, and may be effective to reduce preterm birth rate in multiparous women.

\section{Acknowledgements}

The authors want to thank Prof. Ekkehard Schleußner, Chief Physician of the 
Department of Obstetrics and Gynecology at the University Medical Center of Jena, and Prof. Roland Gärtner, Senior Physician of the Department of Endocrinology at the LMU-University Munich for critical evaluation of the data, and John Lindquist, M.D., Surgeon, Family Practitioner and native speaker, for proof-reading and corrections.

\section{Conflict of Interest}

There is no conflict of interest that could be perceived as prejudicing the impartibility of the research reported.

\section{References}

[1] Blencowe, H., Cousens, S., Chou, D., Oestergaard, M., Say, L., Moller, A.B., Kinney, M., Lawn, J. and Born Too Soon Preterm Birth Action Group (2013) Born Too Soon: The Global Epidemiology of 15 Million Preterm Births. Reprod Health, 10, S2. https://doi.org/10.1186/1742-4755-10-S1-S2

[2] Goldenberg, R.L., Culhane, J.F., Iams, J.D. and Romero, R. (2008) Epidemiology and Causes of Preterm Birth. Lancet, 371, 75-84.

https://doi.org/10.1016/S0140-6736(08)60074-4

[3] Tucker, J. and McGuire, W. (2004) Epidemiology of Preterm Birth. BMJ, 329, 675678. https://doi.org/10.1136/bmj.329.7467.675

[4] Langhoff-Roos, J., Kesmodel, U., Jacobsson, B., Rasmussen, S. and Vogel, I. (2006) Spontaneous Preterm Delivery in Primiparous Women at Low Risk in Denmark: Population Based Study. BMJ, 332, 937-939. https://doi.org/10.1136/bmj.38751.524132.2F

[5] Slattery, M.M. and Morrison, J.J. (2002) Preterm Delivery. Lancet, 360, 1489-1497. https://doi.org/10.1016/S0140-6736(02)11476-0

[6] Berbel, P., Mestre, J.L., Santamaría, A., Palazón, I., Franco, A., Graells, M., González-Torga, A. and de Escobar, G.M. (2009) Delayed Neurobehavioral Development in Children Born to Pregnant Women with Mild Hypothyroxinemia during the First Month of Gestation: The Importance of Early Iodine Supplementation. Thyroid, 19, 511-519. https://doi.org/10.1089/thy.2008.0341

[7] Korevaar, T.I., Schalekamp-Timmermans, S., de Rijke, Y.B., Visser, W.E., Visser, W., de Muinck Keizer-Schrama, S.M., Hofman, A., Ross, H.A., Hooijkaas, H., Tiemeier, H., Bongers-Schokking, J.J., Jaddoe, V.W., Visser, T.J., Steegers, E.A., Medici, M. and Peeters, R.P. (2013) Hypothyroxinemia and TPO-Antibody Positivity Are Risk Factors for Premature Delivery: The Generation R Study. Journal of Clinical Endocrinology and Metabolism, 98, 4382-4390.

https://doi.org/10.1210/jc.2013-2855

[8] Casey, B.M., Thom, E.A., Peaceman, A.M., Varner, M.W., Sorokin, Y., Hirtz, D.G., Reddy, U.M., Wapner, R.J., Thorp Jr, J.M., Saade, G., Tita, A.T., Rouse, D.J., Sibai, B., Iams, J.D., Mercer, B.M., Tolosa, J., Caritis, S.N. and VanDorsten, J.P. (2017) Eunice Kennedy Shriver National Institute of Child Health and Human Development Maternal-Fetal Medicine Units Network. Treatment of Subclinical Hypothyroidism or Hypothyroxinemia in Pregnancy. New England Journal of Medicine, 376, 815-825. https://doi.org/10.1056/NEJMoa1606205

[9] Lazarus, J.H, Bestwick, J.P., Channon, S., Paradice, R., Maina, A., Rees, R., Chiusano, E., John, R., Guaraldo, V., George, L.M., Perona, M., Dall'Amico, D., Parkes, A.B., Joomun, M. and Wald, N.J. (2012) Antenatal Thyroid Screening and Child- 
hood Cognitive Function. New England Journal of Medicine, 366, 493-501. https://doi.org/10.1056/NEJMoa1106104

[10] American College of Obstetricians and Gynecologists (2015) Practice Bulletin No. 148: Thyroid Disease in Pregnancy. Obstetrics and Gynecology, 125,996-1005. https://doi.org/10.1097/01.AOG.0000462945.27539.93

[11] Stagnaro-Green, A., Abalovich, M., Alexander, E., Azizi, F., Mestman, J., Negro, R., Nixon, A., Pearce, E.N., Soldin, O.P., Sullivan, S. and Wiersinga, W., American Thyroid Association Taskforce on Thyroid Disease during Pregnancy and Postpartum (2011) Guidelines of the American Thyroid Association for the Diagnosis and Management of Thyroid Disease during Pregnancy and Postpartum. Thyroid, 21, 1081-1125. https://doi.org/10.1089/thy.2011.0087

[12] De Groot, L., Abalovich, M., Alexander, E.K., Amino, N., Barbour, L., Cobin, R.H., Eastman, C.J., Lazarus, J.H., Luton, D., Mandel, S.J., Mestman, J., Rovet, J. and Sullivan, S. (2012) Management of Thyroid Dysfunction during Pregnancy and Postpartum: An Endocrine Society Clinical Practice Guideline. The Journal of Clinical Endocrinology and Metabolism, 97, 2543-2565.

https://doi.org/10.1210/jc.2011-2803

[13] Lazarus, J., Brown, R.S., Daumerie, C., Hubalewska-Dydejczyk, A., Negro, R. and Vaidya, B. (2014) 2014 European Thyroid Association Guidelines for the Management of Subclinical Hypothyroidism in Pregnancy and in Children. European Thyroid Journal, 3, 76-94. https://doi.org/10.1159/000362597

[14] Torremante, P., Flock, F. and Kirschner, W. (2011) Free Thyroxine Level in the High Normal Reference Range Prescribed for Nonpregnant Women May Reduce the Preterm Delivery Rate in Multiparous. Journal of Thyroid Research, 2011, Article ID: 905734. https://doi.org/10.4061/2011/905734

[15] Medici, M., Timmermans, S., Visser, W., de Muinck Keizer-Schrama, S.M., Jaddoe, V.W., Hofman, A., Hooijkaas, H., de Rijke, Y.B., Tiemeier, H., Bongers-Schokking, J.J., Visser, T.J., Peeters, R.P. and Steegers, E.A. (2013) Maternal Thyroid Hormone Parameters during Early Pregnancy and Birth Weight: The Generation R Study. The Journal of Clinical Endocrinology and Metabolism, 98, 59-66. https://doi.org/10.1210/jc.2012-2420

[16] Zhao, T., Zhang, X., Chen, B., Liu, A., Zhou, Y., Teng, W. and Shan, Z. (2016) The Effect of Subclinical Maternal Thyroid Dysfunction and Autoimmunity on Intrauterine Growth Restriction: A Systematic Review and Meta-Analysis. Medicine (Baltimore), 95, e3677. https://doi.org/10.1097/MD.0000000000003677

[17] Shah, N.R. and Bracken, M.B. (2000) A Systematic Review and Meta-Analysis of Prospective Studies on the Association between Maternal Cigarette Smoking and Preterm Delivery. American Journal of Obstetrics \& Gynecology, 182, 465-472. https://doi.org/10.1016/S0002-9378(00)70240-7

[18] Ruiz, M., Goldblatt, P., Morrison, J., Kukla, L., Švancara, J., Riitta-Järvelin, M., Taanila, A., Saurel-Cubizolles, M.J., Lioret, S., Bakoula, C., Veltsista, A., Porta, D., Forastiere, F., van Eijsden, M., Vrijkotte, T.G., Eggesbø, M., White, R.A., Barros, H., Correia, S., Vrijheid, M., Torrent, M., Rebagliato, M., Larrañaga, I., Ludvigsson, J., Olsen Faresjö, Å., Hryhorczuk, D., Antipkin, Y., Marmot, M. and Pikhart, H. (2015) Mother's Education and the Risk of Preterm and Small for Gestational Age Birth: A DRIVERS Meta-Analysis of 12 European Cohorts. Journal of Epidemiology and Community Health, 69, 826-833. https://doi.org/10.1136/jech-2014-205387

[19] Glinoer, D. (2004) Increased TBG during Pregnancy and Increased Hormonal Requirements. Thyroid, 14, 479-480. https://doi.org/10.1089/105072504323150859

[20] Glinoer, D. (1997) The Regulation of Thyroid Function in Pregnancy: Pathways of 
Endocrine Adaptation from Physiology to Pathology. Endocrine Reviews, 18, 404433. https://doi.org/10.1210/edrv.18.3.0300

[21] Patel, J., Landers, K., Li, H., Mortimer, R.H. and Richard, K. (2011) Delivery of Maternal Thyroid Hormones to the Fetus. Trends in Endocrinology and Metabolism, 22, 164-170. https://doi.org/10.1016/j.tem.2011.02.002

[22] Jin, H.Y. (2016) Thyroxine Binding Globulin Excess Detected by Neonatal Screening. Annals of Pediatric Endocrinology \& Metabolism, 21, 105-108. https://doi.org/10.6065/apem.2016.21.2.105

[23] Hume, R., Simpson, J., Delahunty, C., van Toor, H., Wu, S.Y., Williams, F.L. and Visser, T.J. (2004) Human Fetal and Cord Serum Thyroid Hormones: Developmental Trends and Interrelationships. The Journal of Clinical Endocrinology and Metabolism, 89, 4097-4103. https://doi.org/10.1210/jc.2004-0573

[24] Greenberg, A.H., Czernichow, P., Reba, R.C., Tyson, J. and Blizzard, R.M. (1970) Observations on the Maturation of Thyroid Function in Early Fetal Life. The Jour nal of Clinical Investigation, 49, 1790-803. https://doi.org/10.1172/JCI106397

[25] Thorpe-Beeston, J.G., Nicolaides, K.H. and McGregor, A.M. (1992) Fetal Thyroid Function. Thyroid, 2, 207-217. https://doi.org/10.1089/thy.1992.2.207

[26] Rajatanavin, R. and Braverman, L.E. (1983) Euthyroid Hyperthyroxinemia. Journal of Endocrinological Investigation, 6, 493-505. https://doi.org/10.1007/BF03348351

[27] Borst, G.C., Eil, C. and Burman, K.D. (1983) Euthyroid Hyperthyroxinemia. Annals of Internal Medicine, 98, 366-378. https://doi.org/10.7326/0003-4819-98-3-366

[28] Laurberg, P. (1984) Mechanisms Governing the Relative Proportions of Thyroxine and 3,5,3'-Triiodothyronine in Thyroid Secretion. Metabolism, 33, 379-392. https://doi.org/10.1016/0026-0495(84)90203-8

[29] Karavani, G., Strich, D., Edri, S. and Gillis, D. (2014) Increases in Thyrotropin within the Near-Normal Range Are Associated with Increased Triiodothyronine but Not Increased Thyroxine in the Pediatric Age Group. The Journal of Clinical Endocrinology and Metabolism, 99, E1471-E1475.

https://doi.org/10.1210/jc.2014-1441

[30] Carpi, A., Bianchi, R., Zucchelli, G.C., Del Corso, L., Levanti, C., Cocci, L.F., Giannessi, D. and Mariani, G. (1979) Effect of Endogenous Thyroid Stimulating Hormone Levels on the Secretion of Thyroid Hormones in Man. Acta Endocrinologica (Copenhagen), 92, 73-84. https://doi.org/10.1530/acta.0.0920073

[31] Yoshimura, M. and Hershman, J.M. (1995) Thyrotropic Action of Human Chorionic Gonadotropin. Thyroid, 5, 425-434.

https://doi.org/10.1089/thy.1995.5.425

[32] Glinoer, D., de Nayer, P., Bourdoux, P., Lemone, M., Robyn, C., van Steirteghem, A., Kinthaert, J. and Lejeune, B. (1990) Regulation of Maternal Thyroid during Pregnancy. The Journal of Clinical Endocrinology and Metabolism, 71, 276-287. https://doi.org/10.1210/jcem-71-2-276

[33] Leylek, O.A., Toyaksi, M., Erselcan, T. and Dokmetas, S. (1999) Immunologic and Biochemical Factors in Hyperemesis Gravidarum with or without Hyperthyroxinemia. Gynecologic and Obstetric Investigation, 47, 229-234. https://doi.org/10.1159/000010111

[34] Biondi, B., Bartalena, L., Cooper, D.S., Hegedüs, L., Laurberg, P. and Kahaly, G.J. (2015) The 2015 European Thyroid Association Guidelines on Diagnosis and Treatment of Endogenous Subclinical Hyperthyroidism. European Thyroid Journal, 4, 149-163. https://doi.org/10.1159/000438750

[35] Casey, B.M., Dashe, J.S., Wells, C.E., McIntire, D.D., Leveno, K.J. and Cunningham, 
F.G. (2006) Subclinical Hyperthyroidism and Pregnancy Outcomes. Obstetrics \& Gynecology, 107, 337-341. https://doi.org/10.1097/01.AOG.0000197991.64246.9a

[36] Labadzhyan, A., Brent, G.A., Hershman, J.M. and Leung, A.M. (2014) Thyrotoxicosis of Pregnancy. Journal of Clinical \& Translational Endocrinology, 1, 140-144. https://doi.org/10.1016/j.jcte.2014.07.008

[37] Sun, S., Qiu, X. and Zhou, J. (2014) Clinical Analysis of 65 Cases of Hyperemesis Gravidarum with Gestational Transient Thyrotoxicosis. Journal of Obstetrics and Gynaecology Research, 40, 1567-1572. https://doi.org/10.1111/jog.12372

[38] Rodien, P., Jordan, N., Lefèvre, A., Royer, J., Vasseur, C., Savagner, F., Bourdelot, A. and Rohmer, V. (2004) Abnormal Stimulation of the Thyrotrophin Receptor during Gestation. Human Reproduction Update, 10, 95-105.

https://doi.org/10.1093/humupd/dmh008

[39] Woeber, K.A. (2002) Levothyroxine Therapy and Serum Free Thyroxine and Free Triiodothyronine Concentrations. Journal of Endocrinological Investigation, 25, 106-109. https://doi.org/10.1007/BF03343972

[40] Ingbar, J.C., Borges, M., Iflah, S., Kleinmann, R.E., Braverman, L.E. and Ingbar, S.H. (1982) Elevated Serum Thyroxine Concentration in Patients Receiving "Replacement” Doses of Levothyroxine. Journal of Endocrinological Investigation, 5, 77-85. https://doi.org/10.1007/BF03350495

[41] Huang, W.S., Kuo, S.W., Chen, W.L., Fuh, M.M. and Wu, S.Y. (1996) Increased Urinary Excretion of Sulfated 3,3',5-Triiodothyronine in Patients with Nodular Goiters Receiving Suppressive Thyroxine Therapy. Thyroid, 6, 91-96. https://doi.org/10.1089/thy.1996.6.91

[42] Desai, M., Irani, A.J., Patil, K. and Pandya, C.S. (1984) The Importance of Reverse Triiodothyronine in Hypothyroid Children on Replacement Treatment. Archives of Disease in Childhood, 59, 30-35. https://doi.org/10.1136/adc.59.1.30

[43] Forhead, A.J. and Fowden, A.L. (2014) Thyroid Hormones in Fetal Growth and Prepartum Maturation. Journal of Endocrinology, 221, R87-R103.

https://doi.org/10.1530/JOE-14-0025

[44] Bianco, A.C. and Kim, B.W. (2006) Deiodinases: Implications of the Local Control of Thyroid Hormone Action. The Journal of Clinical Investigation, 116, 2571-2579. https://doi.org/10.1172/JCI29812

[45] Dubois, J.D., Cloutier, A., Walker, P. and Dussault, J.H. (1977) Absence of Placental Transfer of L-Triiodothyronine (T3) in the Rat. Pediatric Research, 11, 116-118. https://doi.org/10.1203/00006450-197702000-00007

[46] Calvo, R., Obregón, M.J., Ruiz de Oña, C., Escobar del Rey, F. and Morreale de Escobar, G. (1990) Congenital Hypothyroidism, as Studied in Rats. Crucial Role of Maternal Thyroxine but Not of 3,5,3'-Triiodothyronine in the Protection of the Fetal Brain. The Journal of Clinical Investigation, 86, 889-899. https://doi.org/10.1172/JCI114790

[47] Chang, L., Munro, S.L., Richardson, S.J. and Schreiber, G. (1999) Evolution of Thyroid Hormone Binding by Transthyretins in Birds and Mammals. European Journal of Biochemistry, 259, 534-542. https://doi.org/10.1046/j.1432-1327.1999.00076.x

[48] Abuhamad, A.Z., Fisher, D.A., Warsof, S.L., Slotnick, R.N., Pyle, P.G., Wu, S.Y. and Evans, A.T. (1995) Antenatal Diagnosis and Treatment of Fetal Goitrous Hypothyroidism: Case Report and Review of the Literature. Ultrasound in Obstetrics \& Gynecology, 6, 368-371. https://doi.org/10.1046/j.1469-0705.1995.06050368.x

[49] Klein, A.H., Hobel, C.J., Sack, J. and Fisher, D.A. (1978) Effect of Intraamniotic Fluid Thyroxine Injection on Fetal Serum and Amniotic Fluid Iodothyronine Concentrations. The Journal of Clinical Endocrinology and Metabolism, 47, 1034-1037. 
https://doi.org/10.1210/jcem-47-5-1034

[50] Richard, K., Hume, R., Kaptein, E., Sanders, J.P., van Toor, H., De Herder, W.W., den Hollander, J.C., Krenning, E.P. and Visser, T.J. (1998) Ontogeny of Iodothyronine Deiodinases in Human Liver. The Journal of Clinical Endocrinology and Metabolism, 83, 2868-2874. https://doi.org/10.1210/jc.83.8.2868

Submit or recommend next manuscript to SCIRP and we will provide best service for you:

Accepting pre-submission inquiries through Email, Facebook, LinkedIn, Twitter, etc. A wide selection of journals (inclusive of 9 subjects, more than 200 journals)

Providing 24-hour high-quality service

User-friendly online submission system

Fair and swift peer-review system

Efficient typesetting and proofreading procedure

Display of the result of downloads and visits, as well as the number of cited articles Maximum dissemination of your research work

Submit your manuscript at: http://papersubmission.scirp.org/

Or contact ojog@scirp.org 